\title{
The Impact of the Creative Atmosphere of a Group and Individual Motivation on a University Student's Creative Personality
}

\author{
Young Ju, Hur \\ General Education, Namseoul University, 91 Daehak-ro Seonghwan-eup \\ Sebuk-gu Cheonan-si Chungcheongnam-do S.Korea \\ youngju@nsu.ac.kr
}

\begin{abstract}
The objective of this study is to explore the impact of the creative atmosphere that fall under a group's characteristics and the motivations that fall under the individual learner's characteristics on a university student's creative personality. The results of the research show that of the creative atmosphere, as motivation and enjoyment increases by 1 , individual creative personality increases by 2.814 , and of individual motivations, as external motivations increased by 1 , individual creative personality increased by 2.341. Therefore, to improve the creative personalities of university students in the future, this study suggestions developing group-based educational programs and utilizing strategies to induce external motivation.
\end{abstract}

Keywords: Creative atmosphere of a group, Individual motivation, Creative personality of a university student, Creativity education

\section{Introduction}

Today's social environment demands creativity more than any other ability, and because of this, the role of university education has become to cultivate creative talents [1]. In fact, creative contribution is not only socially valuable but as it also can be an important advantage for individuals, it can be claimed that it is natural for universities to strive to improve the creative abilities of students [2]. In addition, many organizations have recently introduced a teamwork-based system to improve the effectiveness and efficiency of work tasks [3][4], and there is increasing interest on the effect of the group's creative atmosphere on individual creativity [5][6][7]. However, it is difficult to find research regarding the group's and individual's characteristics and individual creativity. Therefore, this study seeks to explore the creative atmosphere, related to group characteristics, and how motivation influences individual creative personalities, related to the learner's individual characteristics.

\section{Research content and method}

\subsection{Research target}

The research targets of this study were 112 students attending the 2 general education classes on creativity in 2016 from N University. The general characteristics of the research targets are presented in [Table 1]. These students participated in group activities since March.

Article history:

Received (September 26, 2016), Review Result (November 07, 2016), Accepted (December 26, 2016)

Print ISSN: 2207-5380, eISSN: 2207-290X AJEMR

Copyright (C) 2016 Global Vision Press (GV Press) 
Data collection was conducted in the first week of June 2016. Individual creativity tests, individual motivation tests, and group creative atmosphere tests were conducted without a time limit as a self-examination test.

Table 1. Characteristics of research target

\begin{tabular}{|c|c|c|c|c|c|}
\hline Major & $\mathrm{N}(\%)$ & Year & $\mathrm{N}(\%)$ & Gender & $\mathrm{N}(\%)$ \\
\hline Humanities & $36(32.2)$ & 1 & $33(29.5)$ & Male & $71(63.4)$ \\
\hline Health and Medicine & $26(23.2)$ & 2 & $27(24.1)$ & Female & $41(36.6)$ \\
\hline Sciences \& Engineering & $25(22.3)$ & 3 & $20(17.9)$ & Total & $122(100.0)$ \\
\hline Creative Arts & $25(22.3)$ & 4 & $32(28.6)$ & & \\
\hline Total & $112(100.0)$ & 계 & $112(100.0)$ & & \\
\hline
\end{tabular}

\subsection{Research tools}

\subsubsection{Group atmosphere of a group}

For the creative atmosphere of a group, the recent version of the Creative Climate Questionnaire developed by Ekvall, the Situational Outlook Questionnaire (SOQ) was utilized [8]. Based on the measured results, a factor analysis was performed among the 16 questions. The results and reliability of the rotated factors are presented in [Table 2], and the group creative atmosphere sub-factors are re-named for each question.

Table 2. Factor analysis results and reliability of group creative atmosphere test

\begin{tabular}{|c|c|c|}
\hline Question Number & Renaming & Cronbach $\alpha$ \\
\hline $1,3,4,5,10,15$ & Support Trust & .881 \\
\hline $2,7,9,12,13,14,16$ & Motivaion-Enjoyment & .876 \\
\hline $6,8,11$ & Communication & .887 \\
\hline
\end{tabular}

\subsubsection{Individual motivation}

The Work Preference Inventory, developed by Amabile et al. to evaluate the motivations of children, was adapted to fit the Korean situation [9]. Based on the measured results, factor analysis was performed on 22 questions. The results and reliability of the rotated factors are presented in [Table 3], and the sub-factors of individual motivation are renamed according to its question number.

Table 3. Factor analysis results \& reliability of individual motivation test

\begin{tabular}{|c|c|c|}
\hline Question Number & Renaming & Cronbach $\alpha$ \\
\hline $2,5,6,8,9,10,14,16,18,20,22$ & Internal Motivation & .863 \\
\hline $1,3,4,7,11,12,13,15,17,18,21$ & External Motivation & .824 \\
\hline
\end{tabular}

\subsubsection{Individual creative personality}

In order to measure creative personality, we used a questionnaire developed to measure the creative personality of university students [10]. Based on the measured results, a factor analysis was performed on 35 questions. The results and reliability of the rotated factors are 
presented in [Table 4], and the sub-factors of individual creative personality were renamed for each item. Introversion, emotional instability, and isolation were modified to extroversion, emotional stability, and connectivity due to reverse scoring.

Table 4. Factor analysis results \& reliability of individual creativity test

\begin{tabular}{|c|c|c|}
\hline Question Number & Renaming & Cronbach $\alpha$ \\
\hline $1,2,4,7.8,12,1920,21,23,25$ & Openness & .870 \\
\hline $3,5,6,24$ & Task Commitment & .896 \\
\hline $9,10,13,14,15,16,17,26,29,33$ & Sociability & .836 \\
\hline $27,30,34,35$ & Self-Conviction & .865 \\
\hline $11,18,22,31,32$ & Independence & .818 \\
\hline
\end{tabular}

\subsection{Method of analysis}

The group's creative atmosphere, individual motivation, and individual creative personality are interval scales. A multiple regression analysis using optimal scaling was conducted to determine the effects of a group's creative atmosphere and individual motivation on the individual creative personality. In addition, a multiple regression analysis was performed to analyze the effect of the sub-factors of a group's creative atmosphere and individual motivation on individual creative personalities. The analysis was processed using SPSS 23.0 for Windows.

\section{Analysis results}

\subsection{Influence of group's creative atmosphere and individual motivation on individual creative personality}

The mean and standard deviation of the group creative atmosphere of university students, individual motivation, and the creative personality of university students are presented in [Table 5]. The results of examining the correlation between the independent variable of group creative atmosphere and individual motivation show no correlation of .090 , thus no problems of multicollinearity were present.

Table 5. The mean and standard deviation of the group creative atmosphere, individual motivation, and individual creative personality

\begin{tabular}{|c|c|c|c|}
\hline Category & N & Mean & Standard Deviation \\
\hline Group's Creative Atmosphere & 112 & 58.20 & 4.28 \\
\hline Individual Motivation & 112 & 64.15 & 6.71 \\
\hline Individual Creative Personality & 112 & 113.87 & 12.32 \\
\hline
\end{tabular}

A regression analysis was conducted to test the effect of individual motivation of university students and group atmosphere of creativity of university students on creative personality (see [Table 6]) First, the coefficient of determination $\left(\mathrm{R}^{2}\right)$, which is one of the measures of how well the estimated regression lines fit the observed values from the sample data, is .096. In other words, the regression analysis reveals that $9.6 \%$ of the variation of individual creative personality, which is a dependent variable, is explained by the independent variable of individual motivation and the creative atmosphere of university students. Next, the $F$ value of the regression model of creative atmosphere was 3.223 and judged to be significant. 
As tolerance values are all 0.1 or above, and the variance inflation factor (VIF) values are all smaller than 1.0, this means there is no multicollinearity. In addition, the Durbin-Watson value was 1.884 , satisfying the independence assumption, and the results of examining the scatter plot and P-P plot showed they satisfied the homoscedasticity and linearity.

Table 6. Regression analysis results of the group creative atmosphere and individual motivation's creative personality

\begin{tabular}{|c|c|c|c|c|c|}
\hline Category & $\beta$ value & $\begin{array}{c}\text { Standardized } \\
\beta \text { value }\end{array}$ & \multirow{2}{*}{$\mathrm{F}$} & \multicolumn{2}{|c|}{ Multicollinearity Statistic } \\
\cline { 4 - 6 } & 56.157 & - & $3.130 * *$ & Tolerance & VIF \\
\hline Constant term & .848 & .295 & $3.223 * *$ & .992 & 1.008 \\
\hline Creative Atmosphere & .131 & .071 & .777 & .992 & 1.008 \\
\hline Individual Motivation & \multicolumn{5}{|l}{} \\
\hline$* p<.05 * * p<.01 * * * p<.001$ &
\end{tabular}

The result of this analysis, the multiple regression equation is expressed by the standardized $\beta$ coefficient (standardized $\beta$ value) as follows.

\section{$Y$ (Individual Creative Personality) $=56.157+.848 X_{1}$ (Group Creative Atmosphere)}

The creative atmosphere of the group is significant when other variables are included in the regression equation. In addition, as the sign is positive $(+)$, it can be said that the higher the creative atmosphere of the group, the higher the creative personality of the individual. If the other variable values are the same, as the creative atmosphere of the group increases by 1 , the individual creative personality increases by .848 . However, individual motivation is not significant when other variables are included in the regression equation.

\subsection{Effect of group creative atmosphere and individual motivation's sub-factors on individual creative personality}

[Table 7] shows the constituent factors of university students' group creative atmosphere of support, trust, challenge, enjoyment, and communication, the constituent factors of individual motivation of internal motivation and external motivation, and the mean and standard deviation of the dependent variable of creative personality.

Table 7. Constituent sub-factors of creative atmosphere and individual motivation and the mean and standard deviation of creative personality

\begin{tabular}{|c|c|c|c|}
\hline Sub-factor & N & Mean & Standard Deviation \\
\hline Support-Trust & 112 & 23.0982 & 1.42664 \\
\hline Challenge- Enjoyment & 112 & 24.4196 & 3.03623 \\
\hline Communication & 112 & 10.6786 & 2.41696 \\
\hline Internal Motivation & 112 & 33.8125 & 3.82154 \\
\hline External Motivation & 112 & 30.3393 & 5.45672 \\
\hline Individual Creative Personality & 112 & 113.8661 & 12.32115 \\
\hline
\end{tabular}


First, the coefficient of determination $\left(\mathrm{R}^{2}\right)$, which is one of the measures to measure how well the estimated regression line fits the observed value from the sample data, is .173. In other words, the regression analysis shows that $17.3 \%$ of the variation of the creative personality, the dependent variable, is explained by the independent variables of support and trust, challenge and pleasure, communication, internal motivation, and external motivation. Next, the F value of the challenge and pleasure regression model is 2.814 , and the F value of the external motivation regression model is 2.341 , all of which were found to be significant. In order to investigate the collinearity more rigorously, we examined the tolerance limits and the variance inflation factors (see [Table 8]) Tolerance values are all 0.1 or higher, and the variance inflation factor (VIF) values are all smaller than 1.0, meaning it can be seen that there is no multicollinearity. In addition, the Durbin-Watson value was 1.884 , satisfying the independence assumption, and the degree of scattering and the P-P plot were examined and showed it satisfied homoscedasticity and linearity.

Table 8. Regression analysis results of constituent sub-factors of group creative atmosphere and individual motivation on individual creative personality

\begin{tabular}{|c|c|c|c|c|c|}
\hline \multirow{2}{*}{ Category } & \multirow{2}{*}{$\beta$ Value } & \multirow{2}{*}{$\begin{array}{c}\text { Standardized } \beta \\
\text { Value }\end{array}$} & \multirow{2}{*}{$\mathrm{F}$} & \multicolumn{2}{|c|}{ Multicollinearity Statistic } \\
\hline & & & & Tolerance & VIF \\
\hline Constant term & 56.706 & & $2.671 * *$ & & \\
\hline Support· Trust & 1.319 & .153 & 1.678 & .942 & 1.062 \\
\hline Challenge $\cdot$ Enjoyment & 1.035 & .255 & $2.814 * *$ & .951 & 1.051 \\
\hline Communication & .412 & .081 & .900 & .970 & 1.031 \\
\hline Internal Motivation & .508 & -.157 & -1.745 & .958 & 1.043 \\
\hline External Motivation & .468 & .207 & $2.341 *$ & .996 & 1.004 \\
\hline \multicolumn{6}{|c|}{$* p<.05 * * p<.01 * * * p<.001$} \\
\hline
\end{tabular}

The result of this analysis, the multiple regression equation is expressed by the standardized $\beta$ coefficient (standardized $\beta$ value) as follows.

Y(individual creative personality $)=$

$56.157+2.814 X_{1}($ challenge·enjoyment $)+2.341 X_{2}($ external motivation $)$

Of the sub-factors of group creative atmosphere, challenge enjoyment and one of the subfactors of individual motivation, external motivation, were significant when other variables were included in the regression equation. Also, as the sign is positive, the higher the challenge enjoyment and the higher the external motivation, the higher the individual creative personality. If the other variables are equal, as the challenge enjoyment increases by 1 , the individual creative personality increases by 2.814 , and as external motivation increases by 1 , the individual creative personality increases by 2.341 . However, support trust, communication, and internal motivation are not significant when other variables are included in the regression equation. As a result of comparing of the standardized coefficients (standardized $\beta$ value), it can be seen that of the group creative atmosphere, challenge- enjoyment, followed by external motivation, has the greatest influence on individual creative personality. 


\section{Conclusions}

As the creative atmosphere of the group increases by 1 , the creative personality of the individual increased by as much as .848 , and as the motivation/enjoyment increased by 1 , the creative personality of the individual increased by 2.814. In addition, of the individual motivations, when external motivation increased by 1 , the creative personality of the individual increased by 2.341. Contrasting with previous research that reported internal motivation explained most aspects of creativity, it can be said that Korean university students are influenced by external motivations. In addition, although previous studies viewed creative atmosphere as a factor inducing internal motivation, the results show that activities provided to group members to 'encourage motivation and enjoy creating creative ideas' stimulate external motivation and impacts the increase of creative personalities. Therefore, to improve the creative personalities of university students in the future, this study suggestions developing group-based educational programs and utilizing strategies that induces external motivation.

\section{References}

[1] M. Devanna and N. Tichy, "Creating the competitive organization of the 21 st century: The boundary less corporation," Human Resource Management, vol.29, pp.466-471

[2] J. E. Perry-Smith and C.E. Shalley, "The social side of creativity: A static and dynamic social network perspective," Academy of Management Review, vol.28, pp.89-106, (2003)

[3] E. Sundstrom, "Supporting work team effectiveness," San Francisco: Jossey-Bass

[4] J.H. Ha, B.I. Lee, and H.S. Rye, "Study on the creativity of and individual and a group level, and the effects of rewards in a group level,” Korean Society for Creativity Education, vol.11, no.1, pp.89-107, (2011)

[5] M.D. Mumford and S.B. Gustafson, "Creativity syndrom: Integration, application, and innovation," Psychological Bulletin, pp.27-43

[6] D.K. Simonton, "Age and literary creativity: A cross-cultural and trans-historical survey," Journal of CrossCultural Psychology, vol.6, pp.259-277

[7] T.M. Amabile, "Growing up creative: Nurturing a lifetime of creativity," NY: Spinger-Verlag

[8] S.G. Isaksen and G. Ekball, "Assessing the context for change: A technical manual for the situational outlook questionnaire," Orchard Park, NY: The Creative Problem Solving Group, (2007)

[9] Y.S. Han, "Effects of extrinsic reward and intrinsic/extrinsic motivation on attention and problem solving," Doctoral Dissertation, Graduate School of Daegu University, (2010)

[10] S.K. Lee, "The development and validation of creative personality test for university student," The Korean Journal of Educational Psychology, vol.16, no.2, pp.43-61, (2002) 